\title{
Management of Change in a Psychiatric Ward
}

\author{
By Peter Kennedy
}

\section{Introduction}

A psychiatric ward, like any organization, must be capable of changing to meet new demands. Undue conservatism has repeatedly been blamed for serious shortcomings. Yet change can be dangerous, especially if it is rapid. Such a hiatus of experience may occur that disorganization results, or so much energy is diverted to those parts of the system being changed that vital routine tasks are neglected. Laudable endeavours in community psychiatry have got into difficulties when wards have quickly been depleted of experienced staff who have moved into community care, for which they have much enthusiasm but little experience.

This paper describes a few lessons learned in the process of reorganizing an admission ward. A description and evaluation of the eventual treatment programme established is reported in this month's British Journal of Psychiatry, p. 205. With existing staff resources, duration of in-patient stay in this fourteen-bed ward was halved with much greater emphasis on out-patient care for its annual case-load of over 150 unselected admissions. However, it is believed that the following observations have general relevance for managing change in a ward. The consultant in charge had the unusual privilege of an experienced psychotherapist acting as consultant's consultant in defining management problems.

\section{Monitoring Change}

In retrospect it is apparent that most management problems and their solutions were identified by the consultant in charge in the weekly staff meeting which lasted about 50 minutes. By chance rather than design these meetings were preceded by a group meeting for patients. This arrangement proved fortunate. So often the mood and theme of the patients' meeting was mirrored in the staff meeting. Difficulties that were understood and resolved effectively in one context were similarly resolved in the other, as the following example illustrates.

The nurse who had taken the patients' group reported at the staff meeting that the mood had been one of despondency. Various topics were raised and dropped, but one patient kept reiterating his uncertainty about the meaning of a remark made by the charge nurse, which suggested that a previously agreed plan for that patient's early discharge might have been changed. No one volunteered any opinion on the appropriateness or otherwise of the original decision, and the group ended on this note of helpless uncertainty. The charge nurse, who was present at the staff meeting said that he had not intentionally intimated any change of plan for this patient. But when later he was asked whether he really approved of that patient's early discharge, or indeed of the general ward policy, a vigorous discussion took place. The outcome was unanimous renewal of commitment to the objectives of the ward, but it was acknowledged that some people were uncomfortably inhibited from raising doubts about particular decisions lest it should seem contrary to policy. Further discussion led to explicit agreement that patients and staff alike must be encouraged to discuss doubts and anxieties about any decisions made. When invited to do so patients took up this theme with some alacrity at their next meeting.

This modus operandi went some way towards producing the conditions Jackson (1968) has described in successful hospitals. He pointed out that the extent to which members of an organization were motivated or committed to its objectives depended largely on whether there was a high consensus of opinion in support of the executive. This in turn depended on there being arrangements which allowed individuals to express their satisfactions and dissatisfactions and so influence decision-making.

This was not administration by committee. Reorganization of a ward undoubtedly needs single-minded leadership if new objectives are to be imposed. The warnings against decision-making in multidisciplinary teams, made by the Royal College of Psychiatrists (1977) are particularly relevant during change. However, as Affleck (1978) would have predicted, when the consultant in charge felt so selfassured as to be directive without consultation he lost touch with what was really going on in the ward, even when this did not create antagonism. On the other hand, when his approach was so warm-hearted as to be permissive there was loss of structure, ambiguity in decisions, and development of rivalries between other members of staff.

The collection of data for evaluation of the clinical experiment proved to have additional bonuses for management of it. Interim reports were valuable for maintaining interest, and stimulating self-criticism in the staff group, as, well as for refining procedures. Undue enthusiasm or pessimism was tempered by the facts.

\section{Morale}

Unexpectedly, the lowest point in collective staff morale was reached immediately after the plan for change was first proposed, before any actual steps in reorganization were taken. During the process of change morale rose generally, though individual members of staff or particular professional groups experienced low self-esteem at different times. This pattern, perhaps, suggests the main cause of low morale. 
Repeatedly, it emerged that low morale was related to perceived devaluation of professional skills. The idea of reorganization seemed to dispense with present skills upon which professional identities depended. In consequence everyone felt devalued. The nursing staff, for example, perceived the idea of reducing duration of in-patient stay as reducing the importance of the ward milieu for which they had particular responsibility and in which they took particular pride. It seems obvious in retrospect that if reorganization was to be progressive it must not dispense with available skills but rather facilitate greater efficiency in their application. With more rapid patient turnover the interpersonal and organizational skills required in order to maintain a safe and healthy ward environment needed to be enhanced. That reinterpretation seemed right and logical even at the time, but few were reassured until it was confirmed by experience.

It had to be decided whether to wait, in the hope that everyone would come through the doldrums of anticipation before initiating any changes, or to go ahead, hoping that this would solve the problem. Experience suggests that the latter alternative is to be preferred. Waiting only prolonged the agony. Passivity among staff could reach a dangerous degree of abdication of responsibility. Better to promote change as soon as possible even if the first steps are very small and cautious ones. Morale rose as soon as the consultant took the first initiatives.

Thereafter, if there was a problem of morale it was usually associated with a split in the staff group, some members thinking the ward was going well while others felt pessimistic. The central issue was once again about the evaluation of professional skills. The pessimists were underrating their importance, usually because they saw other members of staff carrying out tasks which had traditionally been their own. The optimists were over-confident, with early enthusiasm but inadequate self-criticism of their performance at such tasks. For instance, the social worker felt redundant when other members of staff took to interviewing relatives more often because the short-stay programme demanded more rapid assessment. The social worker suspected that this task was not being done very well, but hesitated to prick the bubble of confidence surrounding her colleagues. Similarly, the ward registrar became disorganized and despondent when nurses took so keenly to writing the initial history and formulation in the case notes, for which he had previously been entirely responsible.

Any change towards a more community-based treatment programme must involve more role sharing, unless the whole treatment team is to move as a unit from family to family, which is hardly practicable. But it does not follow that any member of a team can take over the professional tasks of any other and do them just as well. It was only after acknowledging this fact that the morale problem and the split in the staff group could be resolved. Over-confidence in handling a new task was tempered by recognition of the need for supervision by the member of the team with the appropriate training and experience. Correspondingly, self-esteem improved when that person assumed the role of supervisor.

It was a mistake of leadership to encourage uncritically those taking over new responsibilities with enthusiasm, in the hope that their enthusiasm would spread to others. The appropriate thing to do was to direct that enthusiasm towards improving performance, by seeking guidance from the demoralized team member with the appropriate training and experience to give it. Not to have supported the social worker in this way, for example, would have been a prescription for letting the standards of social work fall to the lowest common denominator. Other staff, enthusiastic but inexperienced in this role, would ultimately have become disillusioned by a less than optimal performance.

Pierce et al. (1972) collected systematic data on attitudes to the treatment programme in a ward, and showed that patients' views closely reflected those of the staff and varied together over time. This experience confirmed that patients' confidence in the treatment programme depended on staff morale, and that when problems of the latter were sorted out problems of the former were also. More often than not, however, it was difficulties evident in the patients' group that forced the staff to acknowledge their own feelings.

\section{Resistance}

Some resistance is inevitable because reorganization of a ward always imposes uncomfortable uncertainty. Members of staff who were consciously deliberately and overtly opposed to the change, or simply did not wish to take part in it, were not the problem. They could be found more suitable placements in the hospital. It was unconscious or covert resistance that presented the greatest challenge. This was not only a passive resistance or inertia, but also an active process which the 1970 Reith lecturer Donald Shon has called 'dynamic conservatism'. A ritual change in behaviour occurred without in any way altering the end result. Members of staff would 'go through the motions' which looked as if the style of operation had changed, when in fact it had not.

In this instance, where the objective was to reduce duration of in-patient care as far as possible, appropriate changes in the treatment programme were agreed by all staff and put into effect. Each patient was assessed within 24 hours of admission, immediate treatment tasks defined, and an early discharge date set. One member of staff, who could be a nurse, was delegated the responsibility for seeing that all decisions about a patient were implemented. And yet for several months, despite these radical changes, the average duration of stay for patients in the ward fell hardly at all. Decisions were fudged or tasks delayed. Staff indulged in discussions to confirm decisions again and again.

If such behaviour was interpreted in a negative light, as a kind of sabotage, it evoked leadership responses which were counter-productive. It was tempting to expose failure, or 
offer to make further changes in the treatment programme in the hope that something more acceptable and workable could be achieved. Either strategy, however, only increased the uncertainty and personal discomfort which motivated the resistance to change in the first place.

There is another way of interpreting this behaviour which is more likely to be correct and puts it in a much more positive and productive light. It can be seen as practice. Staff needed to go through the motions to familiarize themselves with new procedures, before allowing such procedures to actually affect their patients. And so the correct leadership response was to help individuals analyse their dummy-runs, confirming successful aspects, solving difficulties and so improving self-esteem and building the necessary confidence to act independently towards the desired objective. For example, nurses embarking on out-patient care for the first time in their professional careers needed to confirm and review each tiny step in the management of a patient before they felt confident and safe in acting independently and more decisively.

The actual change in operation of the ward occurred surprisingly suddenly after months of discussion and practice. Average duration of stay for patients fell by half over a period of weeks. Perhaps, it was because people only felt confident in taking the step from practice to the real thing when they recognized that everyone else in the team was also ready to do so. Pierce et al. (1972) also noted the suddenness of the gear change in the ward they studied, which had been incubating plans for a quite different kind of reorganization for some time.

The simultaneous release of internal resistances meant sudden confrontation with external resistances from the institution at large reacting to the change which had just become apparent. There were doubts to be dealt with about whether the ward took its fair share of work load and needed all its staff in view of the low bed occupancy. The case-load had in fact increased. There were pressures on nursing staff to avoid becoming so involved in out-patient care. There were questions about whether the ward could fulfil its teaching commitments with so few in-patients. These were some of the issues about which the institution at large had to be reassured if the unit was to be accepted and the morale of its members to survive. It is fortunate, therefore, that maximal external resistance occurred when the reorganization had just succeeded in achieving its objectives, when staff morale was consequently at its highest. An indicator of the level of confidence in the ward team at that time was the energetic discussion which took place about finding a name for the unit to confirm its new identity.

\section{Confusion}

Inevitably there were periods of confusion while the change was taking place. The anxiety and indecisiveness it engendered in the staff could undoubtedly affect patient management. When confusion was acknowledged by some- one in the staff meeting, it was usually found that most other members of the group were in similar difficulties, as were the patients. A particularly disturbed patient, or a lot of admissions, or absence of staff through illness were the kind of eventualities that taxed the new system. Permitting others to mention and share the experience of anxiety and confusion in the staff meetings was the first essential step in dealing with it. Yet the most obvious and predictable responses to it were rarely helpful and sometimes actually aggravated the situation. At these times it seemed quite reasonable to review the new system and modify it. There were calls for more or longer staff meetings to allow vigorous replanning. But confusion was not reduced by yet more change. A much more sanguine and conservative approach usually solved the problem.

This meant first deciding whether the amount of confusion was within tolerable limits for staff and safe limits for patients. If so, the right course of action was to avoid making any significant revision of the programme. Confusion resolved as staff got used to coping with what was usually a familiar problem within a less familiar system of organization. If the level of confusion was intolerable, threatening disorganization, an immediate foolproof safety manoeurre was essential. Meddling with the new treatment programme could never be relied upon to reduce confusion and was therefore dangerous. The sure answer was for everyone to revert to the familiar roles and duties they had held before any reorganization. Nurses, for instance, ceased to take histories and took on no new out-patients, focussing all their attention on supporting in-patients. The social worker and registrar resumed full responsibility for dealing with relatives and out-patients. Then a cool and calm look could be taken to see why such confusion had arisen. More often than not, no great change in the new system was required now that the incidents that provoked the crisis could be anticipated or avoided in the future.

\section{Leadership}

The focus of this paper has been on the consultant's responses to particular problems, but getting the style of leadership right is equally important. When the ends are clear but the means are not, a kind of dualism may be required. Directive leadership is necessary to maintain a firm sense of purpose for the reorganization. Yet this is not appropriate for determining methods when the change is innovative and none have been established. What Affleck (1978) has called 'sapiential leadership' is required. This means that the leader offers his wisdom, usually based on greater experience, to help others solve problems without assuming that he has encountered the problems before.

Cooper (1979) visited this unit in his survey of crisis intervention services and, in common with other centres experimenting with novel methods, he noted a shift towards a less hierarchical and more informal organizational structure. It is suggested that this may be a necessary adjustment 
during a period of change. The sapiential leader has to be more than usually accessible to facilitate mutual problem solving. The traditional ward hierarchy works well when those at the top are familiar with the problems encountered by those at the bottom and the effects of decisions passed down. It is when there are many new problems about which the consultant can be less sure that he needs more opportunity for informal discussion about what other members of staff are up to and readier criticism of his own efforts to help.

On the other hand it was no good pretending to be other than directive when controversy re-emerged about the main objectives of reorganization after a consensus decision to go ahead had been reached. At best this could impede progress and at worst it could produce paralysing conflict and disorganization. The consultant had to be vigilant, carefully assessing every proposed modification or shift in emphasis in the treatment programme, in the light of whether it was in harmony with the aims of the ward. And yet heavy-handed aggressive leadership was not necessary to veto deviations from the plan. Such deviations normally occurred because individuals were struggling to solve a clinical problem without having time to consider more general implications. Simply to point out that a way of solving a problem was in opposition to the main objectives of the ward was usually enough to direct energies towards finding alternatives. For instance, when a registrar started referring alcoholics to a nearby special unit for treatment of alcoholism this meant retaining these patients in hospital for several weeks longer. He was motivated to do this because of a heavy case-load and anxiety about the poor outcome of his alcoholic cases. When it was pointed out that this pattern of care was contrary to the early discharge policy, and more assistance was offered in managing these out-patients, the registrar was ready and willing to revise his practice.

In combining directive and sapiential leadership, therefore, the consultant need not be a Jekyll and Hyde.

\section{ACKNOWLEDGEMENTS}

I am grateful to all the staff of Ward 1A, Royal Edinburgh Hospital, who shared this experience with me, and to consultant psychotherapist Dr. E. A. M. Wood who helped so much in solving our problems.

The reorganization would not have been carried out without a grant from the Mental Health Foundation to evaluate the new clinical service.

\section{REFERENCES}

AfFLECK, J. W. (1978) Administration and the clinician. In A Companion to Psychiatric Studies (Eds Forrest, Affleck, Zealley). Churchill Livingstone.

COOPER, J.E. (1979) Crisis Intervention and Psychiatric Emergency Services in Europe. W. H. O. Copenhagen.

Gofrman, E. (1961) Asylums. Anchor Books.

JACKsON, J. (1968) Consensus and conflict in treatment institutions. Hospital and Community Psychiatry, 19, 165.

KenNEDY, P. F. and HIRD, F. (1980). Description and evaluation of a short-stay admission ward. British Journal of Psychiatry, 136. 205-215.

Pierce, W. D., Trucketr, E. J. and Moos, R. H. (1972). Changing ward atmosphere through staff discussions of the perceived ward environment. Archives of General Psychiatry. 26, 3541.

Royal College of Psychiatrusts (1977). The responsibilities of consultants in psychiatry within the National Health Service. Bulletin of the Royal College of Psychiatrists. September $\mathrm{p}$ 4-7.

\section{Training Course in Behavioural Psychotherapy}

Both the College and the Association of University Teachers in Psychiatry recognize that experience in behavioural psychotherapy should be an integral part of the training of psychiatrists. There is, however, a shortage of trainers in this field, and to remedy this the AUTP in conjunction with the Institute of Psychiatry is organizing a course designed to increase available training resources. The course is mainly intended for consultants and senior registrars and those of equivalent status, but a limited number of other places may be available.

The course will begin with a two-day workshop from 17 to 18 September, 1980 . This will include the following: theoretical background, demonstration of treatments, and participant practice in small group. (Experience in this workship will be reported to the Annual Conference of the AUTP the next day.) After the workshop participants will be asked to undertake behavioural treatment of their own patients in their own centres, and later also to supervise other trainees. Participants will be supervised in small groups at monthly intervals in half-day sessions over the following academic year. The course is organized on lines which qualify for local funding assistance to applicants under the CPME Advanced Postgraduate Training Scheme.

Cost of the combined workshop and monthly supervision over the following academic year will be available on enquiry.

Applicants should write, including a brief curriculum vitae, to Professor Isaac Marks, Institute of Psychiatry, De Crespigny Park, Denmark Hill, London SE5 8AF, where the course will be held. 